\title{
De espacios circunstanciales a espacios permanentes de deliberación en Urabá: socavando las estructuras de la ciudadanía precaria de la mano de la Fuerza Pública ${ }^{1}$
}

https://doi.org/10.21830/9789585318380.04

\author{
David Roldán Alzate ${ }^{2}$ \\ Universidad de Antioquia
}

\section{Resumen}

En este capítulo se hace una reflexión teórica acerca de la democracia deliberativa en contextos de ciudadanía precaria; además, se presenta el caso de Urabá como una región con dinámicas sociopolíticas sustancialmente importantes para el futuro de Colombia. Se alude al pensamiento estructuralista para comprender el subdesarrollo del país y al constructivismo en la ciencia política, para reconocer posibilidades de cambio a partir del diálogo y la deliberación. La reflexión está permeada por una interpretación del papel de las Fuerzas Militares como coadyuvantes del diálogo y gestoras del mantenimiento de la democracia. Otro elemento transversal es el análisis de la política de seguridad y defensa, basada en el agua como bien estratégico del Estado colombiano, a su vez, clave en la garantía de goce de ciudadanía plena.

Palabras clave: agua; ciudadanía precaria; deliberación; desarrollo sostenible; fuerzas militares; Urabá.

1 Este capítulo hace parte de los resultados del proyecto de investigación doctoral "Excedentes de población y ciudadanía precaria en Colombia" y parte del "Grupo de Investigación Interdisciplinar en Dinámicas Regionales, Cultura y Transformación Social" de la Universidad de Antioquia con código de registro COL0212946 de Minciencias. Los puntos de vista y los resultados de este artículo pertenecen al autor y no reflejan necesariamente los de las instituciones participantes.

2 Politólogo, Comunicador Social-Periodista, Estudiante del Doctorado en Ciencia Política (Universidad Autónoma de Zacatecas). Magíster en Relaciones Internacionales (Universidad de Buenos Aires). Analista político de Colombia y América Latina para empresas públicas y privadas de Colombia. Docente e investigador en análisis del discurso político, educación digital y problemas del subdesarrollo. ORCID: https://orcid.org/0000-0001-7026-0199 - Contacto: david.roldan@udea.edu.co 


\section{Introducción}

Dos siglos después de lograda la independencia de la Corona española, el Estado colombiano no ha podido ejercer total autoridad en su territorio. Ha habido cambios políticos de fondo como la instauración de una nueva Constitución Política en 1991, que amplió la participación política a movimientos alternativos y la fuerza pública ha llegado a todo el territorio con relativa estabilidad y permanencia. No obstante, la precariedad de la ciudadanía permanece, con alta desigualdad y pobreza, especialmente en las zonas apartadas de las grandes capitales. No se logra consolidar los derechos de forma permanente e igualitaria, mediante una estructura económica y social más moderna. Las instituciones de judiciales, sociales y económicas a nivel subnacional son insuficientes para mediar en los conflictos sociales y fomentar mercados legales dinámicos con empleos dignos, lo que da lugar a espacios de difícil control frente a la criminalidad. Colombia ha enfrentado varios enemigos internos en las últimas tres décadas, originados en la rebelión armada, la economía criminal, el paramilitarismo o en fuerzas que combinan todos o algunos los anteriores fenómenos. Hecho que ha dejado un saldo catastrófico de víctimas que han venido siendo reconocidas y reparadas por diversas instituciones nacionales. (García, 1977; Kalmanovitz, 2010; Gutiérrez, 2014; Melo, 2018).

Sin embargo, a pesar del panorama anterior, las nuevas generaciones de ciudadanos, a pesar de vivir en precariedad crónica en la mayor parte del territorio, gracias a la universalización de algunos servicios de asistencia social son más educadas, más saludables y prósperas que las anteriores. Sin duda, se logran nuevas cosmovisiones frente a su entorno, al medioambiente, nuevas relaciones con las instituciones públicas y privadas, con los demás ciudadanos y con las Fuerzas Militares (Cepeda, 2020).

En este capítulo se analizará la paradójica emergencia de la ciudadanía colombiana que delibera en el contexto de la precariedad social, teniendo como camino el debate sobre el desarrollo sostenible y la protección de los recursos estratégicos nacionales en el espacio subnacional. Se formularán algunas hipótesis que buscan animar la discusión acerca de nuevas formas de integración ciudadana frente a estos temas, teniendo como ejemplos algunos procesos 
que se llevan a cabo en la estratégica región biogeográfica de Urabá-Darién (departamentos de Antioquia, Chocó y Córdoba). Se espera, finalmente, visibilizar los puntos de encuentro entre la ciudadanía y las Fuerzas Militares en este proceso, tanto desde el punto de vista de las estrategias institucionales (Ministerio de Defensa Nacional, 2019), como de las experiencias territoriales. El texto tiene un enfoque constructivista y estructuralista, haciendo notar la diversidad de problemas permanentes de la sociedad, la economía y la política, así como las realidades institucionales y las oportunidades de cambio y continuidad dichas instituciones.

El capítulo se divide en tres partes: en la primera se presentan los conceptos que permiten darle carácter científico al análisis, por consiguiente, se estudiarán los conceptos que guían la discusión: Estado colombiano —entendido como una organización en consolidación_-, ciudadanía precaria (Durand, 2010) — comprendida como la forma particular que asume la sociedad en un país como Colombia_-, el desarrollo sostenible — como medio y fin susceptible de transformación a través de la participación ciudadana—, y, finalmente, las políticas de seguridad y defensa del país que se adaptan a todo lo anterior. En la segunda parte se estudiarán las condiciones socioambientales de Urabá actualmente, así como algunos de los agentes que interactúan en la vida social y política de esta rica región (Cuees Urabá, 2019). En la tercera y última parte, se hará una aproximación a las relaciones civiles-militares en Urabá, específicamente en lo que tiene que ver con el control territorial enfocado en la sostenibilidad, la seguridad y la defensa territorial. Se espera concluir con algunas pautas de comportamiento en la construcción de las relaciones civiles-militares, tanto para consolidar el trabajo en seguridad y defensa, como para aportar a una sociedad más democrática y a un Estado más fuerte.

\section{Conceptos}

La propuesta epistémica esbozada a continuación tiene dos fuentes: el pensamiento estructuralista y el constructivismo (Bourdieu, 2012).

Mediante el pensamiento estructuralista se entiende que las categorías Estado, ciudadanía precaria, desarrollo sostenible y política pública de segu- 
ridad y defensa, son partes de un complejo mundo prefigurado por condiciones sociales e históricas determinantes. Esto representa, en el caso colombiano, la histórica dominación colonial, la segregación social, la forzosa formación de instituciones políticas republicanas en medio de la pobreza, la incapacidad militar, la baja productividad y competitividad, así como la dependencia internacional, entre otros (1996, p. 434).

Por otra parte, mediante el pensamiento constructivista, se suscribe la idea de pensar el cambio histórico como una posibilidad latente en las sociedades, expresadas en ideologías y discursos que, en sí mismos son hechos políticos (Parsons, 2010). Comprendiendo las limitaciones estructurales se pueden observar las ventanas de oportunidad mediante las cuales se construye un mundo social más justo, más democrático en los derechos y obligaciones formalmente incorporadas en Constituciones de Estados sociales de derecho, como Colombia, pero materialmente inobservados (García \& Revelo, 2011). En otro sentido, con una mirada crítica sobre los discursos hegemónicos que dan por sentadas verdades pretensiosamente inalienables, se entiende que las sociedades evolucionan únicamente bajo profundos procesos de cambio histórico, originados por factores económicos, culturales, tecnológicos, políticos, entre muchos otros, unos más duraderos o transformadores que otros. Con todo, se espera poder dilucidar procesos de diálogo político y comportamiento institucional, tanto en la ciudadanía como en las fuerzas militares, que conduzcan a la construcción de una sociedad más democrática.

En este texto se entiende al Estado como un conjunto de relaciones sociales, donde entran en conflicto grupos de interés económico, cultural y político. En la evolución de esas relaciones emergen históricamente instituciones que modelan el desarrollo de los medios productivos, integran las identidades existentes en los territorios alrededor de un ideal nacional, y administran unos recursos naturales y construidos para lograr los objetivos de los grupos de interés.

De otro lado, se entienden como recursos nacionales todos aquellos que provee la naturaleza para la sostenibilidad de la sociedad, los bienes y servicios públicos y privados, producidos para participar de mercados nacionales e internacionales, las capacidades de trabajo de los ciudadanos, así como los 
títulos del mercado financiero. Los grupos de interés son conjuntos de individuos que actúan socialmente de acuerdo con intereses particulares, bien sea económicos, sociales, políticos o culturales. Estos han alcanzado una enorme heterogeneidad con el avance de las democracias occidentales y la globalización. Aquí se entienden como empresarios, trabajadores organizados o independientes, movimientos ambientalistas, de identidad sexual, movimientos culturales y artísticos, por mencionar solo algunos ejemplos. Todos estos grupos de interés, integrados alrededor de las instituciones del Estado que los representa, conforman la ciudadanía (García et al., 2016).

Colombia —así como muchos otros países de América Latina en general - posee dos características del Estado entendido como relación social (Osorio, 2012, pp. 29-55): la primera es la dificultad histórica para desarrollar los medios productivos necesarios para incrementar sustancialmente sus ganancias en los mercados nacionales e internacionales. Es decir, ni los recursos naturales, ni las capacidades humanas son aprovechados en su máxima potencia, o son depredados y malgastados. La segunda es la desigualdad estructural en la asignación de los recursos nacionales entre todos los ciudadanos; persiste una abrumadora acumulación de medios productivos (recursos naturales y capacidades humanas) en pocas manos. El aprovechamiento de los medios productivos nacionales está destinado predominantemente al rentismo, sin perspectivas nacionales de desarrollo sostenible que brinden garantías de bienestar para la mayoría de la población. La forma de explotación de los recursos naturales se da por medio del extractivismo minero-energético y la agroindustria; mientras que la forma de acumulación por medio de la explotación de las capacidades humanas se da por medio de la flexibilización y la informalidad laboral (mejor entendida como producción de población excedente en contextos de baja productividad y crecimiento), predominantemente con bajos salarios debido al escaso valor agregado de la mayoría de productos o servicios, frente a los países desarrollados. La forma de organización del Estado ha permitido la persistencia de esta realidad, con un lento proceso de reducción de la pobreza, más no de la desigualdad estructural en el país (Figueroa, 2014; García, 1977).

En segundo lugar, se realizará una aproximación al concepto de ciudadanía precaria (Durand, 2010). En este sentido, cabe recordar que el Estado 
suele tratar de aliviar las deficiencias en las condiciones de vida de su población por medio de la asignación directa de recursos para las sectores más pobres, esto, mediante programas de asistencia social que no curan la enfermedad del subdesarrollo ni tampoco le dan sostenibilidad a la sociedad. La consecuencia más clara de esta práctica habitual, es la vulnerabilidad de la mayor parte de la población ante pandemias, desastres naturales o crisis económicas. Todo ello conduce a la caracterización de las relaciones políticas entre el Estado y una ciudadanía precaria. Este tipo de ciudadanía toma la forma las acciones colectivas y políticas que no logran satisfacer las condiciones de bienestar prescritas para un Estado social de derecho, hecho que se presenta por seguir un modelo de desarrollo insuficiente y unas relaciones sociales de producción que brindan pocas oportunidades para la mayoría de la población, a la que se le impide acceder a la garantía de empleo digno, de salud, de educación, de seguridad personal, entre otros derechos.

Que la ciudadanía sea precaria no implica que no exista, de hecho, Colombia presenta atributos notables como la ininterrumpida celebración de comicios para la elección popular de autoridades subnacionales y nacionales, lo que evidencia una democracia procedimental relativamente estable, excepcional en América Latina (Gutiérrez, 2014). Esta democracia procedimental también es precaria y parcial, debido a la exclusión — ejercida por medio de la violencia física y simbólica - a la que se han enfrentado algunos sectores políticos, razón por la cual persiste la intención —entre distintos grupos de interés - en tratar de consolidarla y mejorarla, con el fin de impedir la imposición de gobiernos autoritarios. En este sentido, es plausible el interés de todos los sectores políticos colombianos, incluidos los que se integraron a la legalidad después de procesos de desmovilización, en fortalecer la democracia y reducir la precariedad de la ciudadanía por la vía pacífica e institucional. El carácter precario de la ciudadanía también se hace evidente en el carácter clientelista del sistema político, aunque con una distinción epistemológica que vale la pena señalar: en su acepción básica, la formación y consolidación del clientelismo no es un proceso exclusivo del subdesarrollo, sino que se observa en todo tipo de regímenes democráticos (es decir, la formación de clientelas electorales a partir de la entrega de burocracia o contratos públicos). El patrón que sí se observa 
con más fuerza en el subdesarrollo es la aparición de un clientelismo apalancado en la precariedad de la ciudadanía, para lograr los cometidos políticos; en otras palabras, más allá de la entrega de burocracia o contratos públicos, la competencia por el poder implica manipular a los electores con medios de sobrevivencia, viviendas dignas, o directamente con dineros dirigidos a la compra de voluntades de líderes sociales, que en sus territorios negocian votos el día de elecciones. Esta ciudadanía precaria, condenada a la ausencia de deliberación por sus carencias materiales o por la coacción de violentos, es el soporte de la democracia colombiana, lo que ha llevado, en la práctica, a la elección de líderes antiéticos.

En tercer lugar, se discutirá el concepto "desarrollo sostenible", que la Organización de Naciones Unidas (2020) define como aquel que permite la satisfacción de necesidades presentes sin afectar las futuras, mediante un equilibrio entre crecimiento económico, bienestar de la sociedad y protección ambiental. Pues bien, en Colombia la satisfacción de las necesidades de toda la población ha sido siempre insuficiente, toda vez que ni la producción nacional, ni los recursos con los que cuenta el país, ni las instituciones estatales han estado encaminadas a resolver los problemas de pobreza, exclusión, desigualdad estructural de la sociedad y depredación de los recursos naturales. En otras palabras, no hay un modelo de desarrollo sostenible nacional. En este contexto, estar por debajo de ese tipo ideal pone a la economía nacional en condición de subdesarrollo, dejando claro que el logro del desarrollo enunciado está afincado en la innovación y la competencia para la producción de bienes y servicios que mejoren la situación de las generaciones actuales, sin que esto perjudique a las futuras. Proceso en el cual, Colombia y América Latina participan como colonias industriales (Figueroa, 2014; Robinson, 2013; Serrano, 2016).

A pesar de las adversidades mencionadas, el desarrollo sostenible permite poner en marcha un conjunto de herramientas que resultan fundamentales para alcanzar el objetivo de construir una sociedad democrática. Es decir, en un régimen democrático, solucionar los problemas sociales y ambientales mencionados pasa por reforzar el modelo de desarrollo sostenible, implementar mejores prácticas ciudadanas, empresariales, laborales y políticas. La 
sostenibilidad social y económica es el resultado de acuerdos sociales sobre la forma de explotación de los recursos naturales y humanos, asunto que difícilmente se puede lograr bajo un régimen autoritario en el cual se privilegian únicamente los intereses de un reducido sector de la sociedad.

Una vez explicada la realidad de la ciudadanía colombiana, en la situación precaria y de subdesarrollo en la cual se encuentra la mayor parte de la sociedad, se propone la lectura constructivista de los mismos conceptos como objetivos sociales a lograr por parte de los colectivos. Se plantea así, la alternativa de entender el proceso de transformación estructural de un país como Colombia a partir de la consolidación de la ciudadanía y la democracia como atributos de los sujetos políticos—, y del desarrollo sostenible — como estrategia y marco de actuación de los sujetos económicos-. En otro sentido, se da por descontado que el régimen democrático, la ciudadanía y el desarrollo sostenible ofrecen las mejores alternativas para el logro de la sostenibilidad y el bienestar, a pesar de que se reconozca la imposibilidad de que su emergencia sea plena y absoluta en todo tiempo y espacio.

En cuarto lugar, se entiende la política de seguridad y defensa nacional como el conjunto de estrategias estatales que hacen viables los deberes y derechos expresados en la Constitución Política y las leyes, por medio de acciones de defensa y seguridad, atributos indelegables e irrenunciables de cualquier Estado moderno (Poulantzas, 1979). Las Fuerzas Militares colombianas se han ceñido institucionalmente a la Constitución Política de 1991 y se las ha reconocido como una de las instituciones más sólidas de Colombia. ${ }^{3}$

\section{Urabá: arquetipo}

El caso de Urabá es trascendental para la observación de la realidad colombiana del posconflicto. Bajo la perspectiva de la ciudadanía precaria, en Urabá se distinguen numerosas relaciones económicas, sociales, ambientales y políticas que sirven como modelo interpretativo aplicable a cualquier región subnacional colombiana, especialmente a aquellas que están más aisladas

3 Reputación que solo se ha puesto en duda tras los lamentables delitos, dolorosos para toda la nación, conocidos como ejecuciones extrajudiciales. 
físicamente de capitales departamentales, donde hay mayor concentración de poder. Las relaciones mencionadas obedecen a condiciones estructurales de precariedad de la ciudadanía, observadas en lo territorial (relación con el medio físico natural y construido), económica (los medios de vida) y sociocultural (las relaciones identitarias), pero también a espacios circunstanciales de deliberación que van en contraflujo de las adversidades estructurales, de carácter permanente, que fueron mencionadas. Estos espacios circunstanciales de deliberación facilitan entornos de subjetivación constructivos de nuevas realidades, aunque con escasa capacidad de transformación de las condiciones estructurales de la sociedad y la economía. La medida del contraflujo, entre lo permanente y lo circunstancial, depende del poder de los sujetos políticos que operan en uno u otro espacio, y allí las autoridades del Estado cumplen un papel legitimador fundamental (Cuees Urabá, 2019).

\section{La pesada estructura de la precariedad en Urabá}

Para entender lo que sucede en Urabá se deben comprender las siguientes dimensiones entrelazadas: la primera — que soporta a las demás_ es la dimensión territorial (entendido el territorio como un medio físico, tanto natural como construido por el hombre), que vincula los conflictos por recursos naturales, necesarios para la vida humana, con la sostenibilidad ecológica y la producción agroindustrial. Allí aparecen realidades complejas como el notable crecimiento de la urbanización en el eje bananero (municipios entre Chigorodó y Turbo), la construcción de infraestructuras viales y portuarias, el crecimiento de cultivos agroindustriales y ganadería, la deforestación del Nudo de Paramillo para actividades legales e ilegales, así como del Bajo Atrato para la minería ilegal y la tala indiscriminada de bosques.

La segunda es la dimensión económica, relacionada con la persistencia del modelo de desarrollo basado en la explotación de recursos naturales, la escasa inversión en ciencia y tecnología para la transformación productiva, en un contexto de precarización laboral y producción permanente de excedentes de población (trabajo informal), que somete a la mayor parte de la ciudadanía a ciclos estructurales de pobreza, vulnerabilidad y desigualdad económica. Al 
mismo tiempo, motivada por la rentabilidad que ofrece la nueva infraestructura vial y portuaria, se ha desbordado la especulación inmobiliaria en las fronteras de Carepa y Apartadó, para la construcción de vivienda suntuaria o de uso industrial en los alrededores de los centros urbanos sembrados de banano, zona declarada por el Plan de Ordenamiento Territorial (POT) como suelo urbano. Lo que supone un freno para el desarrollo de una ciudad más incluyente, más integrada, con mejor espacio público. Los actores económicos de la región no han trascendido las buenas intenciones para crear nodos de transformación productiva urbana; tampoco han llegado a la región empresarios externos que instalen industrias con valor agregado, que permitan la vinculación de las nuevas generaciones de profesionales de la región. En el resto del territorio persiste la economía campesina empobrecida, debido a la dependencia de la costosa intermediación para la distribución de sus productos, especialmente cacao y plátano. Solo en el norte, en Necoclí y Arboletes, se observan intermitentes procesos de desarrollo turístico, altamente vulnerables a la inseguridad personal, a los avatares del cambio climático y las pandemias. El Estado resulta ser uno de los principales actores económicos en Urabá, teniendo en cuenta que las transferencias directas y los subsidios a la producción agroindustrial, así como a otras actividades económicas, mantienen el flujo financiero que permite el consumo y los bajos niveles de inversión (Cuees Urabá, 2019).

En síntesis, Urabá presenta importantes ganancias para el sector agroexportador y de ganadería, oportunidades de inversión de largo plazo en el sector inmobiliario, desarrollo moderado del sector servicios ligado a la creciente urbanización, pero escaso cambio productivo o agregación de valor en productos industrializados. Las tensiones entre el capitalismo agroindustrial y los trabajadores formalizados han sido moderadas en las últimas décadas, gracias a acuerdos sindicales que merecen estudios detallados en sus resultados e impactos en la vida económica. Las tensiones sociales que se dan entre la población excedente (Figueroa, 2014), la economía criminal y el Estado, son una bomba de tiempo que explota regularmente debido a inconformidades coyunturales, pero que expresan una crisis estructural. Esto ocurrió, por ejemplo, tras la instalación de peajes de cobro vehicular para financiar la construcción y el mantenimiento de la vía que cruza la región, cobros que 
afectaban los ingresos de la población local (El Tiempo, 2018). Los conflictos de tierra están pasando por un momento crítico, esto, debido a sentencias judiciales contra capitalistas agroindustriales, que ven afectados sus intereses en zonas de alta valorización, las cuales han subido de precio gracias a las ventajas que ofrece la zona portuaria internacional para la exportación de productos (El Espectador, 2020). La precarización laboral y la producción de excedentes de población mantiene a la mayor parte de la ciudadanía en un alto nivel de pobreza y/o vulnerabilidad, lo que resulta paradójico si se toma en cuenta que esto sucede en la misma sociedad en que crecen simultáneamente procesos de cambio cultural y social, parte de la tercera dimensión expuesta anteriormente (Gobernación de Antioquia, 2020)

Justamente, la tercera dimensión denominada sociocultural, tiene que ver con las subjetividades que emergen en Urabá. La mayoría de la población es joven, se trata de generaciones que poco recuerdan o no vivieron el conflicto armado de la década de los noventa, pero que conviven con los conflictos actuales. Persisten grupos armados organizados dedicados a actividades criminales que extorsionan tanto a la economía formal como a la informal, que corrompen las instituciones estatales, y que tienen un efecto devastador para los jóvenes, que por sus carencias son cooptados por la criminalidad organizada para incorporarlos a sus actividades. También el desamparo de familias desintegradas por carencias materiales y violencias de todo tipo impide que las nuevas generaciones incorporen los valores ideales del ciudadano. Se consolidan, así, ciclos de violencia al mismo tiempo que crecen barrios informales en las principales cabeceras, con escasas posibilidades de empleabilidad para sus habitantes, espacios propicios para la degradación social por adicciones, prostitución, violencia intrafamiliar y contra las mujeres, embarazo adolescente, entre otras problemáticas.

\section{Espacios circunstanciales de deliberación: educación, cultura y sostenibilidad}

En la actualidad existen algunas ofertas de educación superior, técnica y universitaria que tratan de cubrir la demanda de enormes contingentes de 
egresados de la educación media y técnica. A 2019 se contaba con una importante oferta de educación superior, aunque deficiente en investigación (Cuees Urabá, 2019). Además, grupos culturales y deportivos surgidos desde iniciativas populares, fomentadas por entes territoriales, por fundaciones privadas o universidades. Estas ofertas acompañan iniciativas de las asociaciones civiles que agrupan víctimas, campesinos, instituciones religiosas, juntas de acción comunal, asociaciones de usuarios de servicios públicos, entre otras, que ejercen sus libertades de expresión, movilización y asociación, bajo el ideal de solucionar las carencias económicas, la ausencia de espacios de participación política en debates con el grandes empresarios y líderes políticos en el poder.

En ese proceso, se convierten en sujetos del oportunismo político, del clientelismo, pero también obtienen logros sociales que nutren su experiencia como colectivos. Sus intereses como grupos de presión social transitan entre líderes sociales, se mezclan con otros intereses y llegan, ocasionalmente, a decisiones políticas locales o departamentales que resuelven problemas en sus territorios.

En este punto, es importante explicar en detalle las causas y consecuencias del carácter circunstancial de la deliberación. En primera medida, las causas pueden agruparse bajo la teoría del Estado ampliado de Gramsci, que es retomada por Thwaites (2007), la cual señala que el Estado "articula el consenso necesario a través de organizaciones culturales, sociales, políticas y sindicales que, en el seno de la sociedad civil, se dejan libradas a la iniciativa privada de la clase dominante y en las que se integran las clases subalternas." (p. 147). Lo "circunstancial" de la deliberación está dado por la situación contingente que permanece inalterada en las condiciones de precariedad de la ciudadanía en el contexto del capitalismo. Es decir, la contingencia del goce de una ciudadanía plena implica que, por ejemplo, se pueda acceder, o no, a la educación, la salud y la vivienda. La contingencia está dada por los efectos nocivos que ha traído el capitalismo globalizado y Neoliberal, especialmente en regiones como América Latina, donde el subdesarrollo se expresa en producción de bajo valor agregado, con bajos salarios, escasísima especialización, entre otros factores. Estas contingencias restringen sustancialmente las capacidades para la deliberación en la mayoría de la población, conduciendo a la democracia a un diálogo desigual entre las minorías privilegiadas, excluyendo materialmente 
de las decisiones a las mayorías, o sometiéndolas a enormes riesgos populistas. Como lo expresa Durand Ponte (2010):

la desigualdad que genera el modo de producción capitalista [...] permite acompañar la dinámica de la desigualdad, no sólo la explotación, sino especialmente la exclusión social (Rizo, 2006), que tiene efecto tanto sobre los individuos como sobre la definición de la estructura social e incluso en la viabilidad de la nación. (Durand, 2010. p. 266)

El carácter circunstancial de la deliberación está soportado en el estado de excepción permanente (Durand, 2012). En este orden de ideas, cabe señalar que en el Estado social de derecho la excepcionalidad se da en momentos de emergencia económica o conmoción interior. Pues bien, se puede observar que en América Latina en general, y específicamente en Colombia, la emergencia económica padecida por buena parte de la población, por cuenta de carencias estructurales, se da de forma permanente.

\section{Las Fuerzas Militares en la deliberación democrática colombiana}

Además de los actores incluidos por Thwaites, se debe adicionar a las Fuerzas Militares en el caso colombiano, ya que, aunque no tienen una vocación deliberativa en nuestra democracia, cumplen dos funciones indispensables relacionadas con la misma: en primer lugar, garantizan la viabilidad del proceso y el fin del consenso entre organizaciones; en segundo lugar, protegen la vida y bienes de los ciudadanos; $y$, en tercer lugar, ejercen autoridad para el cumplimiento de la justicia bajo un marco general de paz, desplegado en la Constitución y en la ley. Las Fuerzas Militares no ejercen como jueces ni como legisladores en lo que respecta a los acuerdos sociales, pero sin su presencia y acompañamiento, prevalecería la desconfianza entre los ciudadanos, que buscarían el mejor provecho para sí mismos y no para el colectivo.

Las Fuerzas Militares representan la soberanía del Estado. En el caso de Colombia, el empeño por lograr el monopolio legítimo de las armas, el control territorial y la defensa de los derechos fundamentales, económicos, sociales y ambientales, es insuficiente en cuanto recursos y capacidades. Frente a esto, 
vale la pena destacar algunos atributos de la deliberación que posee la democracia moderna desde la perspectiva del rol ejercido por las Fuerzas Militares.

Se puede afirmar que la principal fuente de información acerca del control territorial proviene de las Fuerzas Militares. En este sentido, las funciones operativas y administrativas que aquellas cumplen deben caracterizarse por la excelencia en la capacidad de generar información veraz, comprobable y permanente, para contribuir a la toma de decisiones de los ciudadanos. Por tal razón, cualquier vulneración a tal capacidad equivale a elevar los riesgos de una deliberación basada en falsedades o verdades parciales, lo que terminaría socavando la democracia.

Empíricamente, puede verse el papel desempeñado por las Fuerzas Militares en la generación de información sobre la seguridad personal en los territorios, para que los ciudadanos se sientan confiados en su vida diaria, en su movilidad; para que inviertan recursos en diversos sectores económicos o para que habiten ciudades y zonas rurales, pues la generación de arraigo e identidad también se relaciona con la sensación de seguridad.

Con respecto a la aplicación de justicia, las Fuerzas Militares han adelantado permanentes procesos de modernización ligados a la tarea de implementación de la Constitución Nacional de 1991. Además, se ha puesto en marcha la política de fomento a las buenas prácticas en derechos humanos en las Fuerzas Militares. A este respecto, se ha observado un interés de todas las administraciones nacionales por proteger la transparencia en temas relacionados con los derechos humanos y las posibles violaciones cometidas contra estos en el contexto del conflicto armado interno o por fuera de este. De hecho, las investigaciones sobre este particular realizadas por medios periodísticos, organizaciones internacionales amigas y ONG nacionales e internacionales enfocadas en DD. HH. ha sido permanente. Los informes sobre crímenes de lesa humanidad tienen incidencia en la deliberación política, tanto así que fueron material estratégico para la firma de acuerdos con fuerzas irregulares y marcos de justicia transicional. No tiene sustento el desdeñar el papel democrático de apoyo a la deliberación de las Fuerzas Militares, ya que, incluso siendo parte de la confrontación, como víctima institucional, ha obedecido las leyes del gobierno civil colombiano y ha defendido a los miembros de todas las tenden- 
cias políticas. Naturalmente, los retos del posconflicto son enormes, pero los logros son un soporte insoslayable de la democracia colombiana.

A continuación, tomando como base experiencias ocurridas en Urabá, se expondrán algunos de los puntos de encuentro que se dieron en los espacios circunstanciales de deliberación, que tuvieron lugar en territorios con precariedad estructural, y cuyo proceso estuvo mediado por la acción de las Fuerzas Militares, como parte de la construcción de la democracia en una de las regiones que reviste mayor interés para la consolidación de la paz de Colombia.

\section{Agua en Urabá: activo estratégico nacional, recurso ciudadano y objeto de deliberación}

La serranía de Abibe está ubicada al final de la cordillera Occidental de Colombia. Es la fuente de agua más importante para el Urabá y el epicentro de la diversidad natural que le brinda un valor para el ecoturismo, que aún no ha sido debidamente estimado, a los municipios de Chigorodó, Carepa, Apartadó y Turbo. Es el espacio vital de comunidades emberá katío y de colonos históricos que hace mucho tiempo atrás se instalaron allí para tumbar bosque y hacer crecer la ganadería y la siembra de cacao.

Por otro lado, la serranía también es el escenario de confrontación entre grupos armados ilegales que promueven la producción de cultivos ilícitos, y es utilizada como corredor estratégico para el tráfico de cocaína y precursores químicos, desde y hacia el golfo de Urabá y el Caribe. Ricaurte y otros (2007) señalan que el carácter estratégico de esta serranía se deriva de ser un "punto natural de encuentro entre el Caribe y el Pacífico colombiano con Centroamérica”. Allí conviven indígenas, colonos y naturaleza, en un "binomio gente-bosque”. Según estos autores, aguas abajo de la serranía se presentan los principales conflictos sociales y por la tierra:

La apropiación del territorio de Urabá, ha constituido el desarrollo de fuertes conflictos no sólo políticos, económicos y sociales, sino también de tipo ambiental que se expresaron en la sustitución de la cobertura de bosques de catival en las zonas de planicies marino-aluviales, cambios en el drenaje, agota- 
miento del agua y la degradación de los suelos por pastoreo en la zona de piedemonte de la serranía de Abibe. (p. 101)

A pesar de los cambios que tuvo la serranía, por cuenta de la colonización para la agroindustria bananera y la ganadería, hasta la década de 2010 la zona había sido favorecida en la protección ambiental por parte de campesinos y, paradójicamente, por el conflicto armado, que impedía la realización de actividades económicas. Pero solo hasta inicios de 2020, Corpourabá intervino con la declaración de zona ambiental protegida al Distrito Regional de Manejo Integrado Serranía de Abibe, con un área de 41.594 hectáreas (El Nuevo Siglo, 2020). Las implicaciones del crecimiento desordenado de las ciudades del eje bananero — donde se genera el conflicto de mayor intensidad debido a la disposición de agua para la agroindustria o para el consumo domiciliario-, son explicadas por Carlos Pinilla Gallego, presidente del Comité Universidad Empresa Estado Sociedad de Urabá:

Bien es conocido que los ríos del eje bananero en verano pierden el $90 \%$ del caudal. Esto ha sido promovido por la deforestación de la serranía de Abibe. A la autoridad ambiental le ha quedado complicado cuidar ese patrimonio. Durante cuatro o cinco meses del año los municipios del eje bananero se quedan sin agua, lo que se ha tratado de compensar con la construcción de pozos, soluciones de corto plazo por sus bajos caudales, con altos costos en su puesta en funcionamiento y mantenimiento.

Se espera el desarrollo de Urabá y una de las principales limitantes para lograrlo es la calidad de los servicios públicos, especialmente la disponibilidad de agua potable y saneamiento básico. Sólo como ejemplo, según el Departamento Nacional de Planeación, el municipio de Apartadó es uno de los cinco municipios que más va a crecer en los próximos 20 ańos por medio de planes parciales. Apartadó tiene 10 planes parciales aprobados, lo que triplicaría la demanda de agua potable.

Hay iniciativas curativas, pero no preventivas para atender la realidad del agua en Urabá. Por ejemplo, traer el agua captada del Río León para abastecer las necesidades del eje bananero, para lo cual hay un proyecto cercano de acueducto regional liderado por el Grupo EPM, con un valor aproximado a 700 mil millones de pesos. Esta es una alternativa curativa del problema de abastecimiento en el eje bananero. (D. Roldán, comunicación personal, 02 de agosto de 2020) 
En el relato de Pinilla se observan las consecuencias de procesos históricos que han excluido a grupos de interés fundamentales, que no han podido participar de los pocos debates ciudadanos que se han dado en torno al uso del recurso hídrico, debates en los que apenas hasta ahora ven la posibilidad de participar, gracias a la presión social.:

Paradójicamente, siguiendo la entrevista con Pinilla, las alternativas para irrigar de agua al eje bananero de Urabá no pasan por proteger el agua proveniente de la serranía de Abibe. Sin embargo, existen múltiples herramientas políticas para proteger este territorio; por ejemplo, la acción de las juntas de acción comunal o de los resguardos indígenas presentes en la zona, para que soliciten protección directamente a la Fuerza Pública o a las alcaldías con competencia territorial. También se esperaría que en los centros urbanos se llevaran a cabo movilizaciones sociales deliberativas, espacios de interacción alrededor del tema del agua en los que haya participación intergeneracional. Lastimosamente, lo anterior no suele suceder o es tan esporádica su ocurrencia que no ha dejado huella. No obstante, la declaratoria de zona ambiental protegida por parte de Corpourabá, legitima un discurso que puede recibir el apoyo ciudadano (un apoyo "desde arriba"), que obligue a la toma de decisiones de diversas instituciones en el sentido de cumplir con el objetivo de la protección.

En este punto cabe anotar que la acción de las Fuerzas Militares tiene una incidencia directa sobre el control de la deforestación en todo el territorio colombiano. Según el Gobierno nacional, el 47\% de la madera que se comercializa en Colombia, es ilegal. En las últimas tres décadas han sido deforestadas ilegalmente 6.9 millones de hectáreas, sin embargo, con la implementación de la Política de Defensa y Seguridad del gobierno de Iván Duque (2018-2022), se ha logrado revertir ese nefasto proceso, con un descenso de $19 \%$ de acciones criminales entre 2018 y 2019. Pues bien, dentro de los centros de deforestación se encuentra el Nudo de Paramillo, que se suma a la mayor parte de áreas protegidas en el territorio nacional. Las empresas criminales ligadas a la deforestación, y otros crímenes ambientales relacionados con fauna silvestre, son denominadas "ecomafias", que no son otra cosa que grupos dedicados a la tala indiscriminada de árboles para el comercio de maderas en el mercado nacional e internacional. Grupos que constantemente burlan a las autoridades 
ambientales que controlan los permisos de tala (El Nuevo Siglo, 2020). Ante esta situación, la acción colectiva de la ciudadanía de Urabá tiene un correlato efectivo en la acción de las Fuerzas Militares, con el fin de consolidar la protección de los recursos naturales.

Ahora bien, en este contexto, vale la pena preguntar cuáles son los mecanismos de deliberación ciudadana que tienen las autoridades estatales (autoridad ambiental, alcaldías, gobernaciones, etc.), para legitimar las acciones de protección medioambiental. Claramente, como se mencionó, los recursos son escasos para proteger la gran extensión del territorio nacional, como sucede en el caso de la serranía de Abibe. Lo que hace de esta labor uno de los retos que deben superarse para lograr la consolidación territorial. Pero, además, cabe preguntar si los ciudadanos que habitan el eje bananero comprenden la necesidad de proteger socialmente la serranía de Abibe, pues, sin lugar a dudas, es la fábrica de agua de Urabá. Asimismo, habría que indagar si los espacios de deliberación por el clima son amplios y si existe un diálogo intergeneracional e interinstitucional al respecto.

Las respuestas a estas y otras inquietudes relacionadas, probablemente, se resumirían en una sola: la deliberación ciudadana alrededor de la protección de la serranía de Abibe es prácticamente inexistente. Por otro lado, son más circunstanciales que permanentes los espacios de deliberación sobre el problema del agua, pues se dan, mayoritariamente, en momentos de sequía o cuando se presentan desastres naturales. No obstante, como se observó anteriormente, la acción de las Fuerzas Armadas, la institucionalidad de Corpourabá y el interés nacional por proteger los bosques mediante la Política de Defensa y Seguridad, son herramientas que han mostrado cierta efectividad, aunque actúan la mayor parte del tiempo de forma desarticulada.

Tal fue el caso de la deliberación circunstancial que se generó después del desbordamiento del Río Apartadó, entre los días 28 y el 29 de octubre de 2019, que dejó aproximadamente 8000 personas damnificadas. Dentro de las causas del desastre registradas, se señaló el deficiente sistema de alcantarillado del municipio, la construcción de viviendas irregulares en los márgenes del río y la falta de control sobre su cauce, que nace en las estribaciones de la serranía de Abibe. (El Espectador, 2019). La presencia de las Fuerzas Militares fue esen- 
cial en la atención de la tragedia, la integración entre comités barriales, alcaldía y empresarios fue trascendental para reducir las muertes entre la población. Se observó una acción ciudadana contundente, pero circunstancial. El desastre quedó como un hecho anecdótico que no implicó la estructuración de deliberaciones permanentes por la protección del medioambiente, ni por la defensa de servicios públicos dignos.

La construcción de visiones de desarrollo sostenible, alrededor de acciones por la protección de los recursos naturales, corresponde a un proceso cultural de transformación ciudadana, que solo se logrará cuando los habitantes del territorio puedan integrar las demandas que le hacen al Estado en sus espacios deliberativos o en la elección popular. En este caso específico, deberían integrarse las demandas por educación, salud, empleo y vivienda digna, con las de la protección a la serranía de Abibe, su fuente principal de agua. Como ya se anotó, no está en las competencias de las Fuerzas Militares convocar a la deliberación colectiva, ni mucho menos deliberar; es la ciudadanía y los entes territoriales los llamados a velar por la protección de los recursos.

El caso de la serranía de Abibe en Urabá, la incidencia del agua en el desarrollo del eje bananero y la expansión de centros urbanos en Chigorodó, Carepa, Apartadó y Turbo, son hechos que revelan la fragilidad de estas sociedades frente a un modelo de desarrollo que devora los recursos. El objeto de deliberación ciudadana está claro: la protección de la serranía de Abibe. Las competencias para la deliberación también están claras, tanto por parte de la ciudadanía, de la autoridad ambiental y de las autoridades municipales, como de las Fuerzas Militares. La construcción de un modelo de sostenibilidad en este territorio tan vulnerable se constituye en el reto que, de ser superado, puede permitir el goce de ciudadanías plenas, no precarias, en el largo plazo. La sociedad en conjunto reconoce la carencia de agua como uno de los principales factores de precariedad en su estatus de ciudadanos, lo que empeora si se toma en cuenta la abundancia del recurso, pero la desigual distribución de este entre domicilios y agroindustria. Es por ello que el conflicto tendría que estar en el primer lugar de la agenda política, no solamente por lo que implica para su suministro del recurso hídrico en el presente, sino hacia el futuro. En este contexto, una deliberación ciudadana permanente, en consulta con las Fuerzas 
Militares para la protección del medioambiente y con el respeto debido de las competencias, resulta fundamental tanto a nivel ético como político.

\section{Macura: un caso de deliberación permanente}

El trasegar de la sociedad hacia el logro de una ciudadanía plena implica socavar las barreras estructurales impuestas por el modelo de desarrollo imperante. Pues bien, en Urabá una de las principales barreras es el mal uso del agua, bien sea por parte de la agroindustria, por la demanda domiciliaria o empresarial. Sobra decir que el agua es un recurso indispensable para la vida, lo que sí se debe indicar es que la garantía de su suministro y su protección es una obligación de cualquier Estado social de derecho. Postular la presencia de una ciudadanía plena en Urabá, por consiguiente, implica dar cuenta de procesos de deliberación permanente. La Mesa de Acuíferos de Urabá (Macura) es un caso significativo de deliberación permanente en Urabá, que desde 2016 se integró alrededor de la formulación del Plan de Manejo Ambiental de Acuíferos (PMAA). Macura es uno de los múltiples casos de acción colectiva en defensa del agua que realiza deliberación permanente. Al respecto, Rivera (2019) comenta que

en contextos internacionales, algunas experiencias de gestión colectiva del agua subterránea aluden a la necesidad de establecer mecanismos de participación y procesos de comunicación que fortalezcan acciones para mejorar las condiciones del acuífero y garantizar el abastecimiento de agua y su conservación para el mantenimiento de los ecosistemas. En este sentido se identifican algunas iniciativas asociadas principalmente a la conformación de grupos de usuarios de aguas subterráneas, dentro de las cuales cabe citar: Los Consejos Técnicos de Aguas (Cotas) (Pimentel, 2010) en el estado de Guanajuato en México. También en Cataluña-España, la conformación de las Comunidades de Usuarios de Aguas Subterráneas (CUAS) (Olivella, 2013) que ha representado un ejercicio de participación de usuarios en la gestión del recurso hídrico. (p. 10)

Las bondades del modelo de deliberación permanente de Macura (denominado por Rivera como "experiencia de participación para la gestión colectiva”) está centrado en tres principios: el primero es el de deliberación a partir 
de información científica, técnicamente validada por profesionales; el segundo es el de igualdad en la deliberación, bajo el cual hay comunicación interpersonal y grupal con una comunicación clara que permite la participación y entendimiento de todos los miembros de la mesa; y el tercero corresponde a la calidad de la organización. Estos principios dan cuenta de la pretensión de permanencia de la deliberación por el compromiso que se asume con el cuidado del conocimiento generado y compartido, y con la organización como principal medio de protección del acuífero. En cuanto a la información, es de resaltar que Macura se basa en un documento institucional validado por investigadores de la Universidad de Antioquia, el Plan de Manejo Ambiental del Acuífero. En lo que respecta a la comunicación, se resalta la presencia en el organigrama de una estrategia de participación y comunicación dirigida a garantizar la igualdad en la deliberación. Frente a la organización, quizás el asunto más sensible, aparecen órganos colegiados como la junta directiva y los comités por zonas.

El carácter permanente de la deliberación se ha logrado, además, por la facilitación de consensos en el modelo de gobernanza. Este atributo no ha sido delegado a una parte interesada en la Mesa, sino que ha sido debatido en la formulación de estrategias y en el diálogo de conocimientos. La Universidad de Antioquia, principal institución en docencia, investigación y extensión de Antioquia, ha aportado la mayor parte del conocimiento, pero no lo habría logrado sin la gestión territorial y administrativa de la Corporación Autónoma Regional de Urabá (Corpourabá). Ambas instituciones se constituyen como partes interesadas — desde su carácter investigativo y administrativo, respectivamente - y convocantes, unidas en la tarea común de ampliar las responsabilidades sociales del conjunto de ciudadanos que se sientan en la Mesa a deliberar. Los denominados actores de la Mesa se dividen en: 1) sector comunitario, donde se encuentran los resguardos indígenas, los acueductos veredales, las juntas de acción comunal y las ONG; 2) sector productivo, integrado por la Asociación de Bananeros de Colombia y otros agroindustriales; 3) sector comercial y de servicios, conformado por empresas productoras y comercializadoras de envases, empresas de acueductos y servicios públicos; 4) sector público, constituido por los entes territoriales y nacionales; y 5) sector educativo, conformado por instituciones de educación básica, media y superior. 
En los balances de Macura se observan dos patrones que permiten situarla como un ejercicio virtuoso de deliberación permanente acerca del tema del agua. En primera medida, se observa un apego irrestricto a la información verificada y al conocimiento científico en la deliberación. Este patrón se evidencia en la postulación de informes permanentes acerca del estado de los acuíferos, pero también en lo que toca a las acciones para mitigar daños y potenciar experiencias positivas. La defensa del conocimiento en la deliberación se lleva a cabo por parte de entidades con intereses específicos, que ejercen una gobernanza propositiva basada en la presión simultánea para la obtención de resultados frente a la protección del agua. En segunda medida, se observa una amplia participación comunitaria, resultado del éxito en la estrategia de comunicación implementada para llegar a las comunidades. Cabe anotar, que no es el interés de este texto recabar sobre los resultados técnicos del proceso de conservación del acuífero subterráneo en Urabá, lo que corresponde a otras disciplinas, lo que sí interesa en el presente análisis es ver la viabilidad, pertinencia y eficacia de Macura como caso de éxito de deliberación permanente.

Como se mencionó anteriormente, la participación de las Fuerzas Militares en ejercicios de deliberación permanente, como en el caso de Macura, pasa por ejercer sus funciones constitucionales de control del patrimonio ambiental y del cuidado del agua, tal y como ocurre en este caso. Pues bien, en Macura ofician autoridades de Policía como los alcaldes, la Gobernación de Antioquia y también tiene asiento el Gobierno nacional. Las estrategias de defensa del medioambiente emanan de estas autoridades, las cuales, en conjunto con la comunidad y en un proceso deliberativo, validan la acción de coerción sobre las amenazas al acuífero y, en general, a todos los recursos naturales. La información que pueden brindar las Fuerzas Militares en entornos como Macura, determinados por información técnica y científicamente comprobada, es fundamental para el sostenimiento de la deliberación permanente.

\section{Conclusiones}

Colombia adolece de una profunda precarización de su ciudadanía por cuenta de factores estructurales: el subdesarrollo de las capacidades produc- 
tivas; la permanente producción de excedentes de población (población informal), ligada a la insuficiente oferta de empleos y a la precarización de las condiciones laborales; la persistencia de un modelo de desarrollo basado en el extractivismo, así como en rentas legales e ilegales; y en la acumulación de capital por vías no institucionales. A lo anterior, se debe añadir que Colombia no promueve efectivamente la ciencia y la tecnología para el cambio productivo y económico, con el conducente costo social del subdesarrollo.

Una de las principales características de este subdesarrollo es el rápido agotamiento de los recursos naturales, por cuenta de un uso desordenado e ilegal de los servicios ecosistémicos. La devastación de los bosques y el uso inadecuado del recurso hídrico es la muestra fehaciente de este dañino proceso. La protección de los recursos naturales debería ser uno de los elementos sustanciales en el marco de la deliberación ciudadana, con el fin de reducir la precariedad en la que viven la mayoría de los ciudadanos en este entorno de subdesarrollo. En Colombia, esta tarea pasa por darle al agua el estatus de elemento estratégico y fundamental dentro de las acciones institucionales.

A pesar de que la ciudadanía sea precaria, existe. Emergen espacios circunstanciales de deliberación ciudadana, así como de elección popular de autoridades locales, departamentales y nacionales. Es decir, se goza de cierta democracia procedimental. Los espacios de deliberación son circunstanciales porque están más atados a eventos negativos para la sociedad — como desastres naturales, por ejemplo- que a propuestas organizativas de largo plazo. Estos debates circunstanciales están más movidos por emociones irracionales que por información científica y conocimiento práctico. Lo que resulta ser un caldo de cultivo propicio para que se socave la democracia y hacer que emerjan autoritarismos.

Las Fuerzas Militares tienen un papel fundamental en la generación y consolidación de procesos de deliberación permanente, así como en el aseguramiento de los recursos naturales del país. La Política de Defensa y Seguridad del Gobierno colombiano está trazada en ese sentido. Las Fuerzas Militares no son deliberativas en la democracia de Colombia, pero sí pueden garantizar procesos técnicos de deliberación, mediante el suministro permanente de información sobre los territorios, el estado de los recursos naturales y el control 
de las amenazas y las violencias contra la biodiversidad. De hecho, actúan de esta manera, como se observa en el trasegar diario de sus operaciones en toda la nación.

En este sentido, Urabá es un espacio trascendental para lograr la pacificación democrática de Colombia. Coincide en este territorio una enorme biodiversidad, una creciente población en las áreas urbanas, amenazas para la integridad y la vida de los habitantes y los territorios, pero también un cúmulo importante de experiencias significativas en materia de deliberación. A pesar de que la mayoría de espacios de deliberación son de carácter circunstancial, y están ligados a las coyunturas políticas o a eventos climáticos extremos, emergen también espacios de deliberación permanente, como Macura. Allí, por medio de la interacción de actores interesados en el territorio, se discute y protege el acuífero subterráneo. Los logros políticos, seguramente, son mayores que los logros efectivos en lo que se refiere a la protección del agua, pero constituye un ejemplo, y un aliciente significativo, que puede ser replicado en otros escenarios.

\section{Referencias}

Bourdieu, P. (2012). Sobre el Estado, Cursos en el College de France, (1989-1992). Editorial Anagrama.

Bushnell, D. (1996). Colombia. Una Nación a pesar de si misma. Planeta.

Cepeda, M. (2020, 9 de agosto). "El poder va a depender del saber". La Silla Vacía. https:// lasillavacia.com/poder-va-depender-del-saber-77871

Comité Universidad Empresa Estado Sociedad (Cuees Urabá). (2019). Plan Regional de CTi+E 2032. Recuperado de: http://bit.ly/planuraba

Durand, V. (2010). Desigualdad social y ciudadania precaria: ¿Estado de excepción permanente? Siglo XXI, UNAM, Instituto de Investigaciones Sociales.

Durand, V. (2012). Estado de excepción permanente. Universidad Nacional Autónoma de México. http://conceptos.sociales.unam.mx/conceptos_final/491trabajo.pdf

El Espectador. (2020, 12 de mayo). Tribunal Superior de Antioquia pide investigar empresarios bananeros del Urabá antioqueńo. El Espectador. https://www.elespectador.com/noticias/ judicial/tribunal-superior-de-antioquia-pide-investigar-empresarios-bananeros-del-uraba-antioqueno-articulo-919143/

El Nuevo Siglo. (2020, 31 de enero). Corpourabá declara 62.022 hectáreas como áreas protegidas. El Nuevo Siglo. https://elnuevosiglo.com.co/articulos/01-2020-corpouraba-decla- 
ra-62022-hectareas-como-areas-protegidas\#:-:text=La\%20Serran\%C3\%ADa\%20de\%20 Abibe $\% 20$ abarca,actividades\%20econ\%C3\%B3micas\%20en\%20la\%20regi\%C3\%B3n

El Tiempo. (2018, 5 de enero). ANI decidió suspender por un mes el cobro en los peajes de Urabá. El Tiempo. https://www.eltiempo.com/colombia/medellin/protestas-en-urabapor-cobro-de-peajes-168414

Figueroa, V. (2014). Colonialismo Industrial en América Latina. La Tercera Etapa. Editorial Ítaca. García, A. (1977). Colombia: Medio siglo de Historia Contemporánea. En P. González (Ed.), América Latina: historia de medio siglo (pp. 178-230). Siglo XXI.

García, M., \& Revelo, J. (2011). Instituciones, conflicto armado y poder político en el municipio colombiano (2001 - 2011). En M. García, J. Rodríguez, M. García, J. Revelo, \& J. Restrepo, Los Estados del país. Instituciones municipales y realidades locales (pp. 12-51). Dejusticia.

García, M., Torres, N., Revelo, J., Espinosa, J., \& Duarte, N. (2016). Los territorios de la paz la construcción del estado local en Colombia. Dejusticia. http://www.dejusticia.org

García, N. (2019). Ciudadanos reemplazados por algoritmos. Calas Maria Sibylla Merian Center.

Gobernación de Antioquia. (2020). Anuario Estadístico de Antioquia 2017. Gobernación de Antioquia. http://www.antioquiadatos.gov.co/index.php/anuario-estadistico-de-antioquia-2017

Gutiérrez, F. (2014). El orangután con sacoleva: cien años de democracia y represión en Colombia. Editorial Debate.

Kalmanovitz, S. (2010). Hechos y relatos de Nación - Salomón Kalmanovitz - Mas allá del café PARTE I - UNAL. YouTube. https://www.youtube.com/watch?v=SaWYXXy6aP4

Melo, J. (2018). Historia minima de Colombia. Editorial Colegio de México.

Ministerio de Defensa Nacional. (2019). Política de Defensa y Seguridad PDS. Ministerio de Defensa Nacional. https://www.mindefensa.gov.co/irj/go/km/docs/Mindefensa/ Documentos/descargas/Prensa/Documentos/politica_defensa_deguridad2019.pdf

Organización de Naciones Unidas. (2020). Desarrollo sostenible. Organización de Naciones Unidas. https://www.un.org/es/ga/president/65/issues/sustdev.shtml

Osorio, J. (2012). Estado, biopoder, exclusión. Análisis desde la lógica del capital. Anthropos Editorial.

Parsons, C. (2010). "Constructivism and Interpretive Theory". En D. Marsh, \& G. Stoker (Eds.), Theory and Methods in Political Science (pp. 80-98). Palgrave.

Poulantzas, N. (1979). Estado, poder y socialismo. Siglo XXI.

Przeworski, A. (1998). Deliberación y dominación ideológica. The Press Syndicate of the University of Cambridge.

Ricaurte, C., Pérez, C., \& Castaño, B. (2007). Las fuentes semilleras de la serranía de Abibe: una estrategia local para el uso y manejo de los bosques indígenas de Urabá. Eolo Revista Ambiental, (12), 101-108.

Rivera, D. (2019). Procesos de participación y comunicación en la gestión colectiva del agua subterránea: caso de estudio Mesa de acuiferos de Urabá Macura. (Tesis de maestría en Gestión 
Ambiental). Universidad de Antioquia. https://www.un-ihe.org/gesti\%C3\%B3n-participativa-del-agua-subterr\%C3\%A1 nea-caso-de-estudio-mesa-de-acu\%C3\%ADferos-de-urab\%C3\%A1-macura

Rizo, A. (2006). ¿A qué llamamos exclusión social? Polis, Revista de la Universidad Bolivariana, 5(15), 1-13.

Robinson, J. (2013). Colombia: ¿¿tros cien años de Soledad? Ensayos de Economía, №43, julio diciembre, (pp. 11-21).

Serrano, E. (2016). ¿Por qué fracasa Colombia? Delirios de una nación que se desconoce a sí misma. Editorial Planeta

Thwaites, M. (2007). El Estado "ampliado" en el pensamiento gramsciano. En M. Thwaites, Estado y marxismo: un siglo y medio de debates (pp. 129-160). Clacso.

\section{Bibliografía consultada}

Boureau for Appraisal of Social Impacts for Citizen Information (BASIC). (2015). Banana value chains in Europe and the consequences of Unfair Trading Practices. http://makefruitfair.org/ wp-content/uploads/2015/11/banana_value_chain_research_FINAL_WEB.pdf

Ocampo, G. (2018). ¿Cuál Estado para cuál ciudadanía? Paradojas y disyunciones de la modernización del Estado en Colombia. Editorial Eafit. 